Jurnal CARE, Vol. 2, No. 2, 2014

\title{
HUBUNGAN PERILAKU PEMAKAIAN LAPTOP DENGAN KEJADIAN COMPUTER VISION SYNDROME (CVS) PADA MAHASISWA ANGKATAN 2009 PSIK FAKULTAS ILMU KESEHATAN UNIVERSITAS TRIBHUWANA TUNGGADEWI MALANG
}

\author{
Ani Sutriningsih 1) \\ Megawati Nur Anggraeni 2) \\ 1), 2) Program Studi Ilmu Keperawatan, Fakultas Ilmu Kesehatan \\ Universitas Tribhuwana Tunggadewi Malang \\ email: ani.sutriningsih@gmail.com
}

\begin{abstract}
Laptop usage can cause a health complaint called Computer Vision Syndrome (CVS). This syndrome is influenced from the application of ergonomics system that is not good for students use the laptops. The purpose of this study is to identify and analyze the laptop usage behaviour with the case (happenings) of Computer Vision Syndrome (CVS) in Student Year 2009 Nursing Science Program Faculty of Health Sciences University of Tribhuwana Tunggadewi Malang. This study is a descriptive correlative study with the cross sectional method. Sampling technique is Simple random sampling with a sample of 67 respondents. Data collection by questionnaire. The results showed respondents had less good laptop usage behaviour: 37 people (55.2\%), the negative Computer Vision Syndrome (CVS): 40 (59.7\%) and based on the results of the Spearman Rank correlation test with 95\% significance p values obtained: 0.000 . This value less than alpha value 0.05 means Ho is rejected so in statistical tests in this study stated there was a significant relationship between the laptop usage behaviour with Computer Vision Syndrome (CVS) case in Student Year 2009 Nursing Science Program University of Tribhuwana Tunggadewi Malang. Based on the above results, for further researcher could be assessed about the relationship of laptop usage behavior with the visual acuity (visual sharpness). Information about the correct laptop usage behaviour and their impact needs to be widely socialized so that laptop users can be avoided from the happening of CVS.
\end{abstract}

Keywords: laptop usage behavior, Computer Vision Syndrome (CVS)

\section{PENDAHULUAN}

Kenaikan minat penggunaan komputer dan laptop di Indonesia meningkat sangat drastis dari tahun ke tahun dan kini yang lebih di minati oleh warga Indonesia adalah komputer jinjing atau laptop. International Data Corporation (IDC) mengadakan riset data penjualan komputer hingga September 2010, jumlah pasokan komputer ke Indonesia mencapai 4,27 juta unit yang terdiri dari 2,88 juta unit $(67,45 \%)$ laptop dan 1,39 juta unit $(32,55 \%)$ komputer atau personal computer (PC). Persentase penjualan laptop terhadap seluruh penjualan komputer baru, mencapai $46 \%$ pada tahun 2008, kemudian naik menjadi $61 \%$ di tahun 2009 yang jelas membuktikan kenaikan drastis minat masyarakat terhadap penggunaan laptop (Prasetyo \& Siringoringo, 2010).

Penerapan system ergonomic yang tidak baik pada mahasiswa yang menggunakan laptop dapat mengakibatkan mata mudah lelah, badan pegal-pegal, dan sering kesemutan. Keseimbangan dari postur tubuh perlu diperhatikan agar seseorang dapat bekerja dengan aman, nyaman dan tahan lama. Menurut Weiner (1992) Postur tubuh yang tidak seimbang dan berlangsung lama dalam jangka waktu yang lama akan mengakibatkan stress pada bagian tubuh tertentu, yang disebut dengan postural stress. Tekanan pada otot bagian leher, bahu, tangan, dan pergelangan tangan dapat menyebabkan postural stress akibat dari postur tubuh yang jelek (Khaled, 2009).

Orang yang menghabiskan waktu lebih dari dua jam di depan Laptop setiap hari akan mengalami gejala Computer Vision Syndrome (CVS). Dalam kebanyakan kasus, gejala CVS terjadi karena tuntutan visual dari tugas melebihi kemampuan visual individu dengan nyaman melakukan itu (AOA, 2006). Computer Vision Syndrome (CVS) mempengaruhi jutaan pekerja kantor, mahasiswa, dan orang-orang pensiunan yang menggunakan computer (Watt, 2003).

American Optometric Association (AOA) mendefinisikan Computer Vision Syndrome (CVS) sebagai masalah mata majemuk yang berkaitan dengan pekerjaan jarak dekat yang dialami seseorang selagi atau berhubungan dengan penggunaan computer. Gejala-gejala yang timbul kemudian dibagi menjadi empat kategori, yaitu gejala astenopia (mata lelah, mata tegang, mata terasa sakit, mata kering, dan nyeri kepala), gejala yang berkaitan dengan permukaan okuler (mata berair, mata teriritasi, dan akibat penggunaan lensa kontak), gejala visual (penglihatan kabur, penglihatan ganda, presbiopia, dan kesulitan dalam memfokuskan penglihatan), dan gejala ekstraokuler (nyeri bahu, nyeri leher, dan nyeri punggung) (AOA, 2006). 
Jurnal CARE, Vol. 2, No. 2, 2014

Ada beberapa penelitian terkait perilaku dan dampak penggunaan laptop, Penelitian pertama di lakukan oleh Straker (2010) dari Curtin University, Australia yang meneliti tentang keluhan yang dirasakan oleh siswa dasar yang menunjukkan bahwa laptop berpotensi menimbulkan keluhan pada punggung dan leher. Penelitian kedua dilakukan oleh oleh Bhanderi et al (2007). mengenai kejadian astenopia pada operator komputer mendapatkan bahwa $46,3 \%$ responden mengalami astenopia saat atau setelah bekerja di depan komputer dengan angka kejadian lebih tinggi pada perempuan. Kejadian astenopia berhubungan secara bermakna dengan usia saat menggunakan komputer, adanya kelainan refraksi, jarak penglihatan, posisi layar monitor terhadap mata, penggunaan layar antiglare, penyesuaian terhadap kontras dan kecerahan pada layar monitor. Penelitian ketiga dilakukkan oleh Octaviani \& Hendra (2007) Hasil penelitian didapatkan $97 \%$ responden mengalami keluhan kesehatan. Bagian tubuh yang banyak dikeluhkan adalah bagian leher, mata, bahu, punggung bagian atas dan pergelangan tangan. Bagian tubuh yang paling sedikit dikeluhkan adalah pergelangan kaki. Diketahui bahwa $91,8 \%$ dari responden yang mengalami keluhan kesehatan termasuk dalam penggunaan laptop yang berisiko tinggi.

Dari studi pendahuluan yang dilakukan peneliti dengan wawancara pada tanggal 4 Januari 2013 kepada 5 orang mahasiswa didapatkan 4 orang mengatakan bahwa menggunakan Laptop yaitu sekitar 4-6 jam perhari, 1 orang menggunakan laptop kurang 2 jam perhari. Responden biasanya menggunakan laptop dengan cara dipangku, menggunakan meja kecil, duduk dilantai, tiduran sedangkan 1 orang menggunakan laptop di atas meja dan duduk dikursi. Dari 3 responden mereka mengatakan jika terlalu lama di depan laptop matanya perih, kabur dan sakit pada leher dan 2 responden mengatakan tidak ada masalah dengan lama penggunaan Laptop.

\section{METODE PENELITIAN}

Desain yang digunakan dalam penelitian ini adalah desain penelitian korelasi yaitu penelitian dengan menggambarkan suatu masalah dengan distribusinya. Pendekatan yang digunakan adalah pendekatan cross sectional yaitu rancangan penelitian dengan melakukan pengukuran atau pengamatan pada saat bersamaan (Notoatmodjo, 2010).

Populasi dalam penelitian ini adalah mahasiswa angkatan 2009 Program Studi Ilmu Keperawatan Fakultas Ilmu Kesehatan Universitas Tunggadewi Malang yang menggunakan laptop sebanyak 81 orang. Teknik pengambilan sampel dalam peneitian ini menggunakan metode Simple random sampling, metode ini dilakukan dengan cara undian berdasarkan NIM mahasiswa angkatan 2009 yang keluar sebanyak 67 orang.

Lokasi dilakukannya penelitian bertempat di kampus Universitas Tribhuwana Tunggadewi Malang. Waktu dilakukannya penelitian pada 24 Juli - 25 Juli 2013.

Variabel bebas dalam penelitian ini adalah perilaku pemakaian laptop yang diukur menggunakan kuesioner yang berisi 8 item pertanyaan yang disusun berdasarkan tinjauan pustaka yang meliputi durasi, frekuensi dan postur saat menggunakan laptop. Sedangkan variabel tergantung dalam penelitian ini adalah kejadian Computer vision syndrome (CVS) yang diukur menggunakan kuesioner. Kuesioner ini hasil modifikasi dari kuesioner Azkadina (2012), berupa sejumlah pernyataan tertulis yang digunakan untuk memperoleh data atau informasi terkait kejadian Computer Vision Syndrome (CVS) Yang terdiri dari 4 pernyataan dengan jawaban "Ya" dan "TIDAK".

Data yang diperoleh dari kuesioner disajikan dalam bentuk tabel distribusi frekuensi. Untuk mengetahui hubungan antara perilaku pemakaian laptop dengan kejadian computer vision syndrome (CVS) pada mahasiswa angkatan 2009 Program Studi Ilmu Keperawatan Fakultas Ilmu Kesehatan Universitas Tribhuwana Tunggadewi Malang di cari menggunakan uji statistika Spearman Rank dengan menggunakan bantuan SPSS 15 for window dengan tingkat kemakanaan 0,05 (Tingkat kepercayaan 
Jurnal CARE, Vol. 2, No. 2, 2014

\section{HASIL DAN PEMBAHASAN}

a. Karakteristik umum responden

Tabel 1. Karakteristik umum responden $(n=67)$

\begin{tabular}{llll}
\hline \multirow{2}{*}{ Variabel } & \multirow{2}{*}{ Kategori } & \multicolumn{2}{l}{ Jumlah } \\
\cline { 3 - 4 } Jenis kelamin & Laki-laki & 41 & $\%$ \\
& Perempuan & 26 & 38.8 \\
Umur (thn) & 20 & 2 & 3.0 \\
& 21 & 8 & 11.9 \\
& 22 & 20 & 29.9 \\
& 23 & 24 & 35.8 \\
& 24 & 12 & 17.9 \\
& 25 & 1 & 1.5 \\
& 26 & 2 & 3.0
\end{tabular}

$\begin{array}{llll}\text { Ukuran } & & 7 & 10.4 \\ \text { laptop } & 10^{\prime \prime} & & \\ & 12^{\prime \prime} & 8 & 11.9 \\ & 14^{\prime \prime} & 52 & 77.6\end{array}$

\begin{tabular}{llll}
$\begin{array}{lll}\text { Penggunaan } \\
\text { kacamata }\end{array}$ & Ya & 10 & 14.9 \\
& Tidak & 57 & 85.1 \\
\hline Jumlah & & 67 & 100 \\
\hline
\end{tabular}

Berdasarkan Tabel 1 sebagian besar responden berjenis kelamin laki-laki (61,2\%), terbanyak berumur 23 tahun (35,8\%), sebagian besar menggunakan laptop dengan ukuran 14" $(77,6 \%)$ dan lebih dari separuh tidak menggunakan kacamata $(85,1 \%)$.

\section{b. Perilaku pemakaian laptop dan kejadian Computer vision syndrome (CVS)}

Tabel 2. Tabulasi silang perilaku pemakaian laptop dengan kejadian Computer Vision Syndrome (CVS) pada mahasiswa angkatan 2009 Program Studi Ilmu Keperawatan Fakultas Ilmu Kesehatan Universitas Tribhuwana Tunggadewi - Malang tahun 2013

\begin{tabular}{llllllll}
\hline \multirow{2}{*}{ Variabel } & \multirow{2}{*}{ Kategori } & \multicolumn{2}{l}{ CVS } & \multicolumn{3}{l}{ Negatif } \\
\cline { 3 - 7 } & & \multicolumn{2}{l}{ Positif } & \multicolumn{3}{c}{ Jumlah } \\
\cline { 2 - 7 } & & $\mathrm{n}$ & $\%$ & $\mathrm{n}$ & $\%$ & $\mathrm{n}$ & $\%$ \\
\hline \multirow{2}{*}{ Perilaku } & Cukup baik & 12 & 17.9 & 25 & 37.3 & 37 & 55.2 \\
& Kurang baik & 1 & 1.5 & 7 & 10.4 & 8 & 11.9 \\
& Tidak baik & 14 & 20.9 & 8 & 11.9 & 22 & 32.8 \\
\hline Jumlah & & 27 & 40.3 & 40 & 59.7 & 67 & 100.0 \\
\hline
\end{tabular}

Berdasarkan Tabel 2 diketahui bahwa dari $55,2 \%$ responden dengan perilaku pemakaian laptop kurang baik cenderung mengalami CVS negatif sebanyak 37,2\% dan CVS Positif sebanyak $17,9 \%$. Responden dengan perilaku pemakaian laptop cukup baik sebanyak $11,9 \%$ mengalami CVS positif $1,4 \%$ dan CVS negatif $10,5 \%$. Sedangkan perilaku pemakaian laptop yang tidak baik cenderung mengalami CVS positif yaitu sebanyak 20,9\% dan CVS negatif $11,9 \%$.

Postur tubuh, durasi dan frekuensi yang tidak sesuai ergonomi akan berakibat pada perilaku pemakaian laptop yang kurang baik. Frekuensi penelitian ini memang lebih banyak berjenis kelamin perempuan dibanding dengan yang berjenis kelamin laki-laki, Perempuan 
Jurnal CARE, Vol. 2, No. 2, 2014

cenderung lebih teliti dan telaten dalam bekerja sehingga mereka akan benar-benar memusatkan perhatian pada pekerjaan yang dihadapi untuk mengurangi tingkat kesalahan kerja. Tuntutan untuk dapat memusatkan perhatian di depan laptop secara terus-menerus menjadi sumber stressor untuk penglihatan maupun psikologis dan akhirnya menimbulkan keluhan-keluhan penglihatan.

Hasil penelitian ini sesuai dengan Saito (2000) bahwa perilaku pemakaian laptop adalah suatu keadaan atau aktivitas seseorang pada saat menggunakan laptop. Cara Penggunaan laptop yang perlu diperhatikan oleh pengguna laptop meliputi postur tubuh saat menggunakan laptop, durasi penggunaan laptop, frekuensi penggunaan laptop. Postur tubuh yang harus diperhatikan saat menggunakan laptop adalah posisi kepala, posisi duduk, posisi tangan dan posisi kaki. Durasi maksimal penggunaan laptop dalam 1 hari adalah 2 jam. Sedangkan Frekuensi penggunaan laptop tidak dapat dipisahkan dengan durasi seseorang saat menggunakan laptop.

Berdasarkan Tabel 2 diketahui bahwa kejadian Computer Vision Syndrome (CVS) yang positif yaitu 27 orang $(40,3 \%)$ dan yang mengalami kejadian Computer Vision Syndrome
(CVS) negatif sebanyak 40 orang (59,7\%). Sehingga dapat di simpulkan dari beberapa data hasil penelitian diatas bahwa kejadian Computer Vision Syndrome (CVS) yang positif akan terjadi jika perilaku pemakaian laptop yang tidak baik yaitu sebesar 32,8\% dan Computer vision syndrome (CVS) yang negatif terjadi jika perilaku pemakaian laptop kurang baik yaitu sebesar 55,2\%. Radiasi laptop juga dapat menyebabkan kelelahan mata dan gangguan mata lainnya, masalah visual lainnya adalah gangguan sakit kepala dan sakit leher atau bahu, selain itu pengguna laptop ternyata lebih jarang berkedip.

Hasil penelitian ini relevan jika dikaitkan dengan teori American Optometric Association (2006) yang mendefinisikan CVS sebagai masalah mata majemuk yang berkaitan dengan pekerjaan jarak dekat yang dialami seseorang selagi atau berhubungan dengan penggunaan komputer. Etiologi CVS menurut Affandi (2005) sebagai berikut, kurang berkedip, koordinasi mata dan pemfokusan yang tidak jelas, komputer sering dipasang sedemikian rupa sehingga membuat mata bekerja terlalu keras (Jenis huruf yang terlalu kecil, pantulan cahaya dari sumber yang didekatnya atau dari jendela mungkin terlalu terang).

\section{c. Hubungan perilaku pemakaian laptop dengan Kejadian Computer vision syndrome (CVS)}

Tabel 3. Analisa statistik hubungan perilaku pemakaian laptop dengan kejadian Computer Vision Syndrome (CVS) pada mahasiswa angkatan 2009 Program Studi Ilmu Keperawatan Fakultas Kesehatan Universitas Tribhuwana Tunggadewi Malang

\begin{tabular}{lllll}
\hline Variabel & $\mathrm{n}$ & $\begin{array}{l}\mathrm{p} \\
\text { value }\end{array}$ & rho & Keterangan \\
\hline $\begin{array}{l}\text { Perilaku pemakaian laptop } \\
\text { CVS }\end{array}$ & 67 & 0.000 & 0.794 & H1 diterima \\
\hline
\end{tabular}

Dari Tabel 3 diketahui bahwa hasil analisis statistik $p$ value sebesar $0,000<0,05$, maka Ho ditolak H1 diterima, artiya : ada hubungan yang signifikan pemakaian laptop dengan kejadian computer vision syndrome (CVS) pada mahasiswa angkatan 2009 Program Studi Ilmu Keperawatan Fakultas Ilmu Kesehatan Universitas Tribhuwana Tunggadewi Malang. Hal ini menunjukkan bahwa terdapat korelasi yang signifikan antara perilaku pemakaian laptop dengan kejadian computer vision syndrome (CVS). Koefisien korelasi sebesar 0,794 menunjukkan besarnya keeratan hubungan antara perilaku pemakaian laptop dengan kejadian computer vision syndrome (CVS). Sehingga jika perilaku pemakaian laptop yang tidak baik maka kejadian computer vision syndrome (CVS) akan positif.

Dalam pengujian korelasi antara perilaku pemakaian laptop dengan kejadian Computer Vision
Syndrome (CVS) didapatkan adanya hubungan yang signifikan, dikarenakan pada table 4.3 dapat diketahui bahwa responden dengan CVS positif yang mempunyai perilaku tidak baik sebanyak $32,8 \%$, cukup baik $11,9 \%$, kurang baik $55,1 \%$. Sedangkan responden dengan CVS negatif yang mempunyai perilaku tidak baik sebanyak $11.9 \%$,cukup baik $11,9 \%$ dan kurang baik $55,1 \%$.

Computer Vision Syndrome (CVS) dapat muncul karena perilaku penggunaan laptop yang tidak sesuai dengan prinsip ergonomi, sehingga tuntutan visual dari tugas melebihi kemampuan visual individu dengan nyaman melakukan itu.Orang yang paling beresiko untuk perkembangan CVS adalah orang-orang yang menghabiskan dua atau lebih jam terus menerus didepan komputer setiap hari (AOA, 2006). 
Jurnal CARE, Vol. 2, No. 2, 2014

Berdasarkan hasil penelitian yang telah dilakukan Computer Vision Syndrome (CVS) Positif paling banyak dikarenakan perilaku pemakaian laptop yang tidak baik yaitu sejumlah 32,8\% dan Computer Vision Syndrome (CVS) negatif paling banyak pada perilaku pemakaian laptop yang kurang baik yaitu sejumlah 59,7\%. Hal ini disebabkan karena responden tidak bisa membedakan antara keluhan akibat Computer Vision Syndrome (CVS) dengan keluhan sakit kepala biasa, Serta lembar kuesioner yang belum baku juga mempengaruhi hasil dari penelitian.

Orang dapat mampu melakukan cara pencegahan atau pengurangan masalah kesehatan akibat CVS menurut Affandi (2005) adalah meletakkan monitor $40-60 \mathrm{~cm}$ dari mata, monitor sebaiknya dipasang 10-20 lebih rendah dari mata, berusahalah berkedip lebih sering. Untuk menghindari kejadian CVS pada pengguna laptop perlu memperhatikan standar ergonomi dan melakukan pencegahan terjadinya CVS

\section{KESIMPULAN}

1. Perilaku pemakaian laptop pada mahasiswa angkatan 2009 Program Studi Ilmu Keperawatan Fakultas Ilmu Kesehatan Universitas Tribhuwana Tunggadewi Malang sebagian besar dengan perilaku kurang baik sebanyak 37 orang $(55,2 \%)$.

2. Kejadian Computer Vision Syndrome (CVS) pada mahasiswa angkatan 2009 Prohgram Studi Ilmu Keperawatan Fakultas Ilmu Kesehatan Universitas Tribhuwana Tunggadewi Malang sebagian besar dengan Computer Vision Syndrome (CVS) negatif sebanyak 40 orang $(59,7 \%)$.

3. Hasil uji statistik penelitian ini menyatakan ada hubungan yang signifikan antara perilaku pemakaian laptop dengan kejadian Computer Vision syndrome (CVS) pada mahasiswa angakatan 2009 Program Studi Ilmu Keperawatan Fakultas Ilmu Kesehatan Universitas Tribhuwana Tunggadewi Malang.

\section{UCAPAN TERIMA KASIH}

Terima kasih disampaikan kepada mahasiswa angkatan 2009 Program Studi Ilmu Keperawatan Fakultas Ilmu Kesehatan Universitas Tunggadewi Malang yang telah berpartisipasi dalam penelitian ini serta pihakpihak yang telah memberikan ijin dalam pelaksanaan penelitian.

\section{DAFTAR PUSTAKA}

Affandi, ES. 2005. Sindrom Penglihatan Komputer (Computer vision syndrome) Majalah kedokteran Indonesia, Vol. 55, pp 297-300, <http : $/ /$ mki.idionline.org/ $>$. Diakses 8 januari 2013.

American Optometric Association (AOA). 2006. Computer vision syndrome (CVS). Pp. 1-4. http://www.aoa.org/. Diakses 8 januari 2013.

Azkadina, A. 2012. Hubungan antara faktor resiko individual dan komputer terhadap kejadian Computer Vision Syndrome. Dalam: Jurnal Media Medika Muda.

Hendra \& Octaviani, DF. 2007. Keluhan Kesehatan Akibat Penggunaan Laptop Pada Mahasiswa FKM UI. (Jurnal Kesehatan).

Notoatmodjo, S. 2010. Ilmu Perilaku Kesehatan. Rineka Cipta. Jakarta.

Notoatmodjo, S. 2010. Metodologi penelitian kesehatan. Rineka Cipta. Jakarta.

Prasetyo, H \& Siringoringo, L. 2010. Tahun depan laptop, masih paling top. Kontan . http:// proyeksi. Kontan.co.id/v2/read/industry/55//Tahun -Depan-Laptop-Masih-Paling-Top. Diakses 4 januari 2013.

Saito, S. Bruno, P. Michael, J., et al. 2000. Ergonomic Guidelines for Using Notebook Personal Computers [on line]. Industrial Health, 38, 421-434 dari : http://www.jniosh.go.jp/english/indu_hel/ pdf/IH38_55.pdf.Diakses 7 januari 2013.

Simarmata, J. 2006. Pengenalan Teknologi Komputer dan Informasi. ANDI. Jakarta.

Straker. 2010. Evidence-based guidelines for the wise use of computers by children:physical development. Ergonomics, 53, 458-477.

Watt, WS. 2003. Computer vision syndrome and computer glasses .http://www.mdsupport.org/library/cvs.ht ml. Diakses 7 Januari, 2013. 